\section{Understanding of the Informal City: \\ Its Interruptions, and Generative Activations}

"When we started living in cities, we did something that had never happened before in the history of life...We broke away from the equations of biology...Every other creature gets slower as it gets bigger. That's why the elephant plods along. But in cities, the opposite happens. As cities get bigger, everything starts accelerating. There is no equivalent for this in nature. It would be like finding an elephant that's proportionally faster than a mouse." ${ }^{1}$

Geoffrey West,

Distinguished Professor and Past President Sante Fe Institute

\section{CONTEXT:}

By setting the context of this studio and of this paper it will allow the readers to understand not only the situation in which the architecture educators and practitioners had over the course of the studio, but will also emphasize and clarify how a pedagogical construct was able to be developed out of situational problems that occur with the students and how that would further guide and enrich the city and urban design research the studio performed and how it can have the potential contributions to the academe and the practice of architecture. This design studio was a 10-week summer urban studio that was a continuation from a semester-long seminar course taught in Lima, Peru in a collaborative setting between students from different architecture, planning, and real state programs from Peruvian

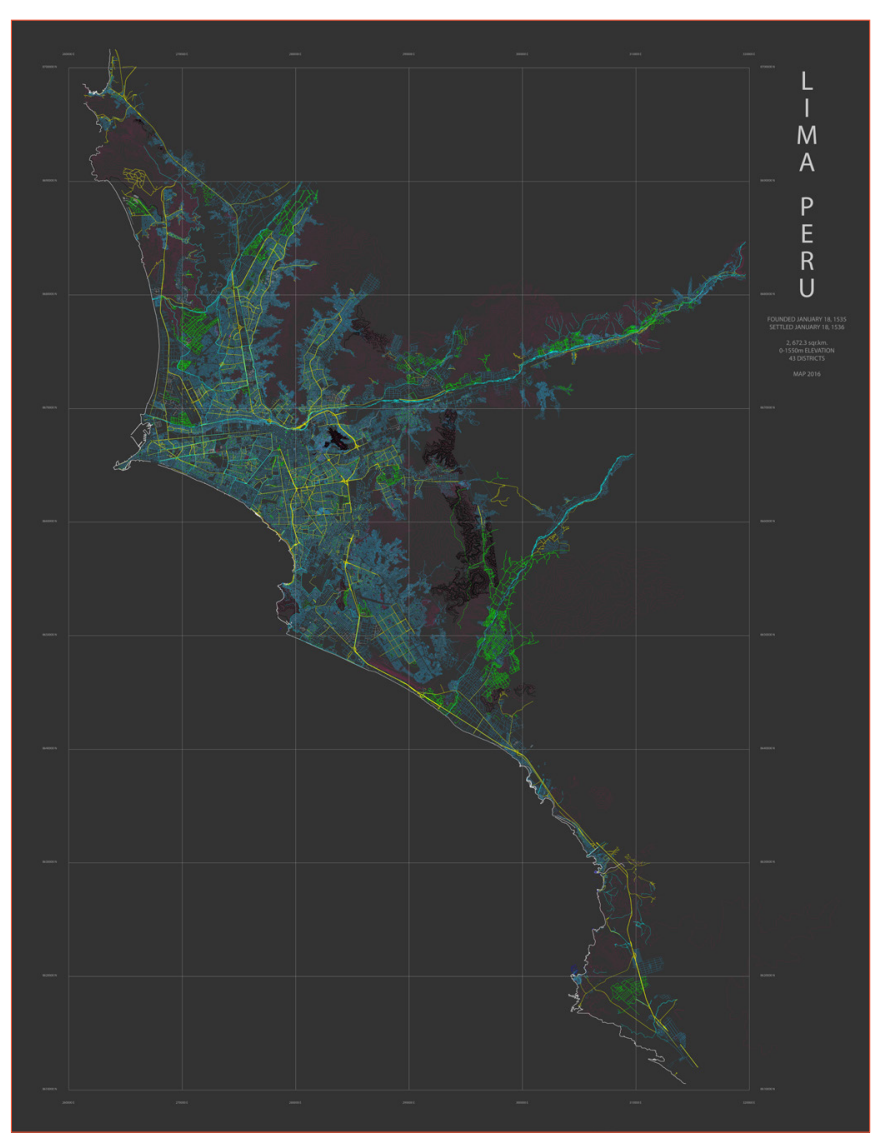

Figure 1. Map of Metropolitan Lima \& El Callo, Peru. (Drawing by author)
David J. Isern

Texas Tech College of Architecture 


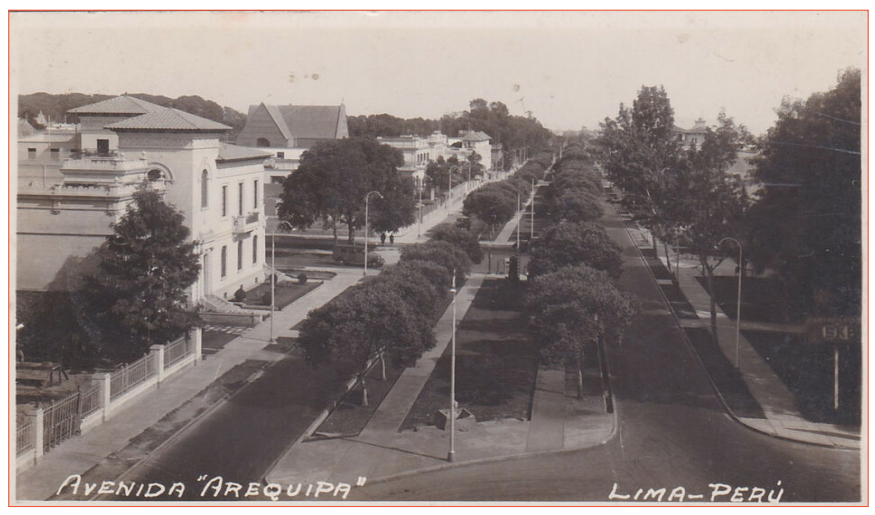

Figure 2. Arequipa Avenue, Lima, Peru. (Avenida "Arequipa", 1940, Postcard, Author's personal collection)

universities, upper-level architecture, urban design, and planning students from American, English, Spanish, and Australian universities, and in collaboration with the city of Lima.

During the previous semester seminar, the students were asked to look at the historiography of conditions of exclusion and marginality in Latin America, using the city of Lima as their main case study. Through their analysis and design approach, students were able to find expressions of urban growth magnified by changes in urban segregation. Furthermore, the city's patterns of self-sustaining economic development that had taken place in the last decade coupled with the rapid growth and allocation of resources that took place between the elite and the marginal developments of the city, further demonstrated how the city of Lima was becoming part of the 21st century and how it could accommodate and compete with other cities from across the world. Although the seminar looked and used in-depth racial classifications to analyze the city, its inhabitants, and evolution, as well as developed a pedagogy and ultimately many innovative proposals that looked at the city of Lima with new light and started to address relevant issues present in many other Latin America cities, a problem arose clearly. There was a significant disjunction between the understanding of the city and the outcomes and benefits of the seminar's findings, and proposals developed from the local students and the international students. The disjunction was due to a misunderstanding of what an informal city is and how the proposals can be realized. This misunderstanding also emphasized the different perspectives brought with different schools of thought, methods, and practices.

Therefore the summer studio looked to find a common and shared understanding to create a baseline for the narrative between the different points of view, to help mitigate and provide a clear understanding to all students of their findings; creating tools that allowed them to apply their findings through actual and real implementations in the city.

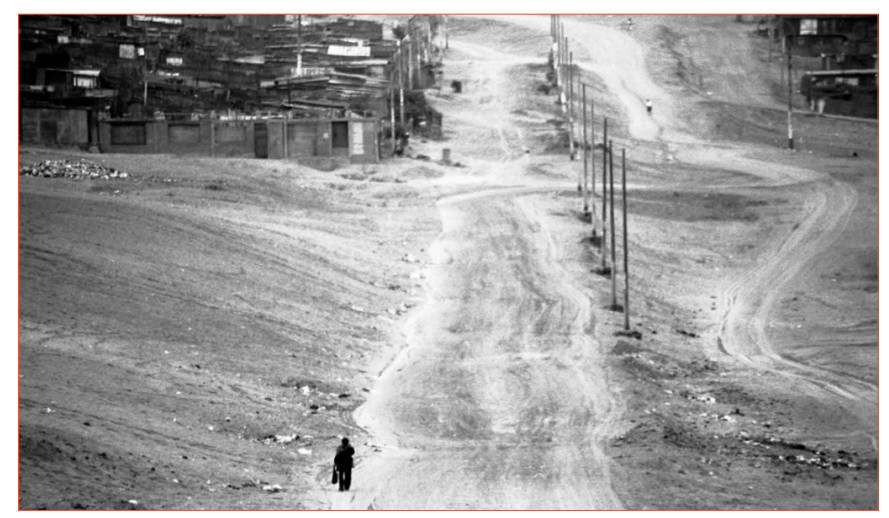

Figure 3. Road leading to "Pueblo Joven" or Informal Settlement.

\section{SETTING:}

Through the eyes of many, American and Western cities are designed as mitigators between the ideas of continuity and uniformity. These cities are promoted and incentivized by not only the local government but also from the people who live in them. The continuity and uniformity, become part of the more extensive arrangements of multi-leveled elements that provide the inhabitants of a city with amenities, commodities, and comfort services that try to create an ideal city - and perhaps do away with the space for living realities.

When looking at Latin American cities; however, it is essential to look at them with and counter perspective, regardless of where the initial perspective comes from. ${ }^{2}$ Therefore, the antithesis of being continuous and uniform is to be interrupted. It is in these interruptions where people become aware of the episodes the city creates because of their contradictory nature to global ideals. These episodic interruptions contain a narrative of the people who live in the cities and a narrative of every event that takes place, minuscule or prominent, and that affects the city's behavior, creating an ultimate and actual reality of the city and its narrative. This summer studio looked at the post-industrial transformation of Latin America cities, in particular, the city of Lima, Peru. ${ }^{3}$ The studio examined the questions of how cities in Latin America can oscillate between the North American and Western pragmatism, regulatory, and standard development, and the emergent informalities that create and drive the progress of many of the cites that we see today in Latin American countries. (Figure 2 and 3 )

Looking at the city of Lima, we begging to understand that the informality of the city is based upon the pre-Colombian, Colonial, and post-industrial invasion and migration narratives that alter the previous established hegemonic and lately erratic narratives of the city. These events of informality, are independent interrupters to the uniformity and continuity of the once designed colonial and preindustrial city. 
Students begin by analyzing these informalities and how they have affected the horizontal field of the city of Lima. Through these analyses, the students begin to understand the nuanced oscillations the city has and how they contrast to the North American and Western canonical and well-studied models. This process allowed all of the national and international students to create a standard understanding of the "informal city." By creating a parading, we stared to discussed cohesively ideas that address the following fundamental questions:

1. Do people realize that they are characters in the grand narrative of the city?

2. Are these characters aware that they can become interrupters themselves?

3. How much of these interruptions are needed in the city to have the reality come to life? Moreover, how can proposals be realized?

Although in part analytical and speculative in nature, through the process of using Lima's analysis of the historiography of exclusion and marginality and an in-depth mapping methods, the students started to be placed at the center of the problems of the informal city - to develop an accurate and real understanding of them regardless of where their first ideas came from. Through this process, the students no longer understood the city through a biased or myopic lens, weather one of insensibility of the informalities because as nationals they were fully immersed in the informal developments and were not aware of how these interruptions were distinct from the broader field of the city and the global context, or the perspective of an international student whose ideas of the informal city is grounded in case studies, post-rationalization, or an outsidelooking-in perspective.

Looking at how interruptions occurred, and how they have become nuanced interims or breaks in the city, the students started to create a fundamental language that all of them were able to understand and agree upon. This process allowed the students to form the basis for new design proposals and improvements to their previous studies.

\section{THE HUNCH:}

The hunch posed on this studio and by the faculty, and with the hopes to test it again to keep the possibilities of improvement and developments happening, is that individuals who are versed in architecture, urban or general design theory can theorized architecture and urbanism and developed proposals that are coherent and thorough, but lack the applicability and shared understanding. The studies proposed during the previous semester seminar were theorizations of the city at a distance and from an analytical-solution driven approach that is not necessarily fully understood by everyone, and therefore failed to generate solutions that can have the potential to be realized in the city.

The real question became, what is the one thing that all students can understand and relate to collectively. The ideas of being, reality, occurrence, and events that take place in a city were the concepts the studio focused on.

Further, urban memories and ad-hoc methods found

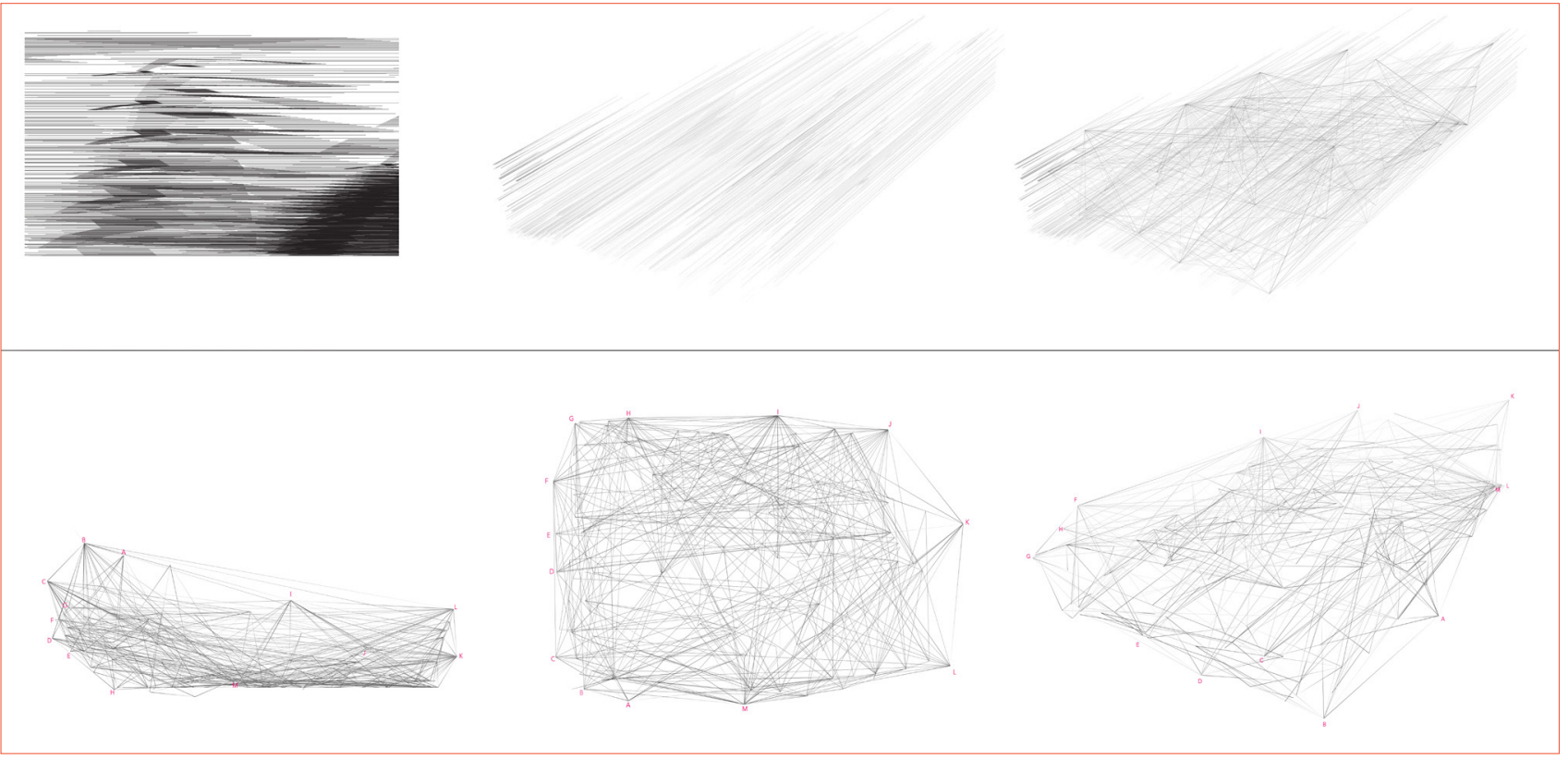

Figure 4. Ontological system scans and spatial development. (Drawings by author) 
in many Latin American countries helped emphasize the ideas of informality and generate a common understanding of informal developments in many cities. These developments are singular nodal moments, or as mentioned before, interruptions in the city's field. Therefore, there was a need to find a starting point, a baseline that is understood by all students and allows them to generate real systems that give the informal cities the natural ability to grow in their own methods. The systems needed to maximize the understanding of the city's organization, assemblage, and replication methods of the current urban systems to be able to generate, test and adapt new proposals.

This baseline needed to be about actual memory and theory that provided clues that help shape the future of the cites as a combination of historical events and innovative practices that allows for new traces to actively take place.

\section{DESIGNING THE SYSTEMS:}

Once all students had a true baseline understanding of the city both at the actual and with a theoretical construct, the studio process introduced the students to the formal ideas of systems, stimuli, and ontologies as a metaphysical relation between the state of being and the idea of becoming. [Figure 4]

Ontology is the philosophical study of being, with an overarching concept directly relating to the aspect of becoming, existing, and more importantly of becoming real. It is here that students are able to translate their findings of the city, the ad-hoc interruptions they discovered in their mappings and field studies in a physical and metaphysical form - all based in reality and objective perspectives, creating a system inherit of the analysis. Their once speculative notion and approach to the informal is no longer salient. Now a system that

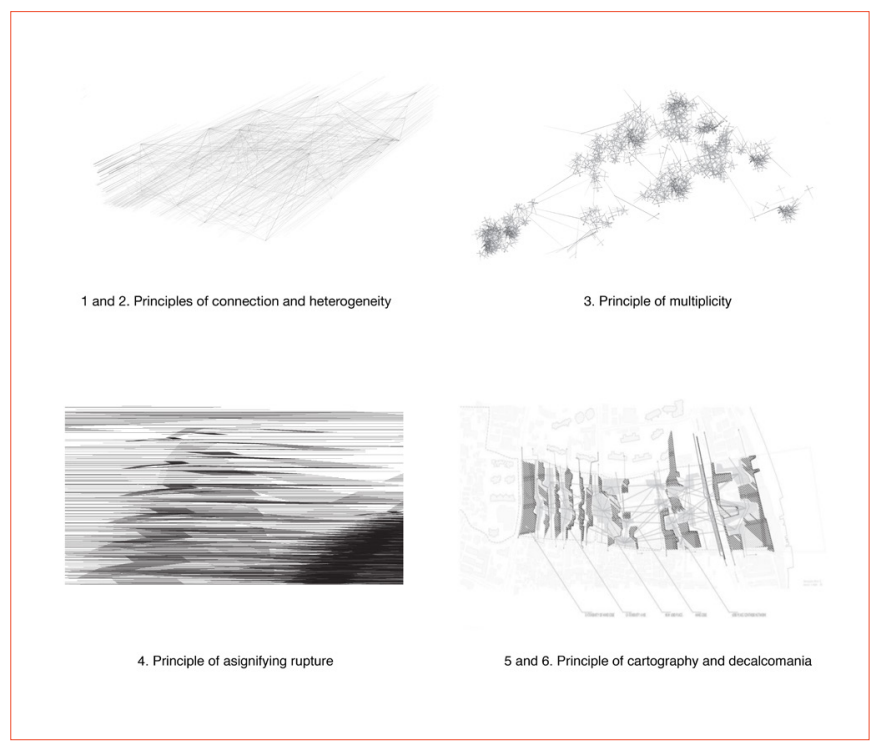

Figure 5. Rhizomatic translation and language implementation on informal urban development. (Drawings by author) can stimulate and create new methods and processes is generated.

Following these ideas, and the hunch, the process tasked to the students with revisiting the idea of memory and the city. The studio faculty instructed the students not to forget or negate ideas of memory and experience of the city as valid and powerful data sets and theoretical abstracts. Rather, the students needed to include social memory and experience as a crucial element that allowed the proposals to develop the capacity for showing the effects and the results of past physical treatments, and how they have affected all the inhabitants of the city both physically and metaphysically. This information was then encoded using the theoretical application and constructs the students used as part of their seminar studies to create a new method of understanding the city.

With the newly found information, the students were able to revisit and further develop the mappings they had produced in the seminar. In their new iterations, these mappings start to codify and explain the character of the city and all its informalities and interruptions through the analysis of physical structures such as buildings, city infrastructure, formal and informal developments; as well as movement and field patterns of land occupation, ownership, and control. These mappings were driven by the theoretical ideas founded on the previous steps but directly correlated to the physical manifestation in the city. These mappings do not try to prove themselves truer or more accurate than any other map, rather the mappings highlight and contribute to new traces and memories that can take place in the city.

The students then design self-generating tools that create new field-networks of development. These self-generating tools create a catalog of systems - site-less and scale-less modules that can partake independent of their relationship to the city they once belonged to but are encoded with information that is singularly applied and collectively associated to actual effects in the field of the city.

In this phase, we introduced narratives of Gilles Deleuze's Difference and Repetition, as well as the ideas of the Rhizomes established by Deleuze and Guattari in their book A Thousand Plateaus: Capitalism and Schizophrenia. We also looked at Manuel Delanda's ideas of biological organisms and social agents, Anibal Quijano classification of racial exploitation, Geoffrey West ideas of nature, growth, and equations of biology, and Charles Waldheim landscape urbanisms theories to help organize and narrate the new fields and maps.

As a foundation to all the theoretical narratives we looked at during the studio analytical and design process, the students focused on ideas relating to Deleuze and Guattari's six rhizomatic principles, they are the following: [Figure 5]

- 1 and 2. Principles of connection and heterogeneity: "...any point of a rhizome can be connected to any other, and must be" 


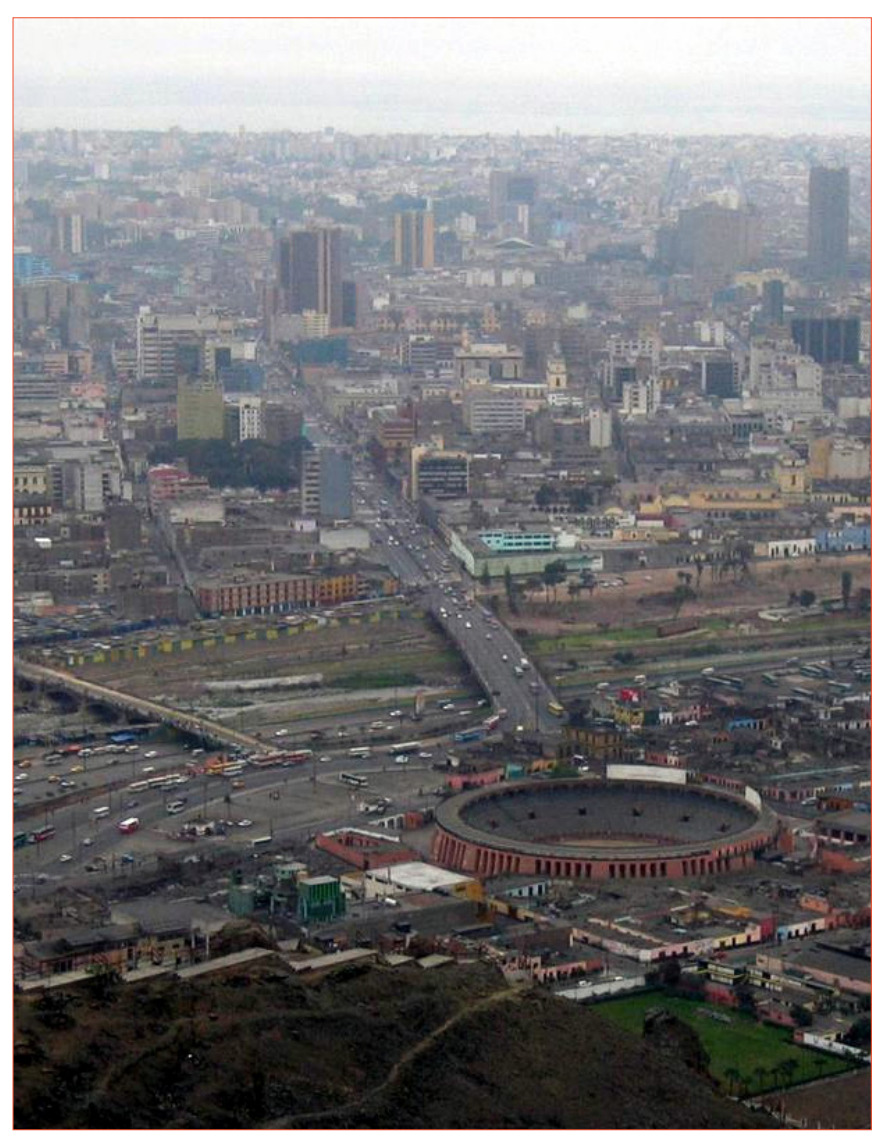

Figure 6. View of Plaza de Acho, District of Rimac, Lima, Peru depicting the formal and informal settlements co-existing in the field of the city.

- $\quad 3$. Principle of multiplicity: it is only when the multiple is effectively treated as a substantive, "multiplicity," that it ceases to have any relation to the One;

- 4. Principle of asignifying rupture: a rhizome may be broken, but it will start up again on one of its old lines, or on new lines;

- 5 and 6. Principle of cartography and decalcomania: a rhizome is not amenable to any; it is a "map and not a tracing." "

Taking Deleuze and Guattari's rhizome principles into account and applying them to the creation of new city fields of actions, the following relationships are formed. [Figure 5] The city is an assemblage of multiple programs and agents operating in response to the different and often conflicting logics that take place in time but are interconnected under one physical manifestation - the field and surface of the city - Connection and Heterogeneity.

Cities have within agglomerations of "very diverse acts, that include linguistic, perceptive, mimetic, gestural, and cognitive." These acts create a multiplicity of activities, physical and metaphysical, that do not relate to one another and no longer reinforce the idea that cities are for a singular use - Multiplicity.
Cities have the ability to go beyond their boundaries by the gaps created - the city's interruptions; therefore, they able to extend beyond the political and economic hegemonies that are already established by the top-down history and political culture, creating larger networks of regulations based on new social-spatial relationships - Asignifying Rupture.

Cities are a surface, both singular and holey that can start to establish a standard of development and congested actions, creating a map that can be followed no matter the physical location. This cognitive and extemporaneous understanding of the space promotes interactions between agents and time, regardless of where any character start or finish - Cartography.

Once the students designed and compiled their self-generating tool catalogs, they start to use their mappings to measure and test the urban space and their relationship to density, measuring the city's interruptions to the initial city's field. In other words, students used their self-generating tools to start to mesh theoretical and analytical strategies of coexistence and stimuli with the systems of the city, highlight potential places of interruption and potential for new developments.

\section{OUTCOME:}

As we continue through this process and enter into the last phase of the studio, the students started to create new stimuli and events, in other words, students start to create new traces and new memories in the city as actualized interventions. At this stage, the students take their projects from an isolated analytical sequence of city narratives and start to activate them as part of the field of interruptions they have discovered. It is at this point that through speculative and diagrammatical analysis, the students started to understand the informal city and its realities by using the potential implementations of that came from the outcomes and benefits of the work they had produced. The urban field of the city becomes a living and real organism, creating an oscillation between design as thought and activation as physical manifestations.

The idea behind this studio is to understand that Latin American cities, and in this case Lima, Peru, is based on memories and ad-hoc methods and that theoretical and analytical solution-driven approaches are not necessarily fully understood by the national students. This understanding is not posed as a criticism of the students or their architecture and urban design education; instead, it highlights the different types of schools-of-thought, methods, and solutions that students can bring.

Informal cities, for the most part, have become containers of spontaneous, erratic, and abstract infrastructures, field conditions, cultural ecosystem, events, and queries that operate in a social and geopolitical regime that cannot be formalized or fully design. These cities are fundamentally established as informal and self-generative. 
The ability to test new systems, that generate new stimuli and propose new traces and memories with the realities of the current informal city starts to create potential realities for future proposals. [Figure 6]

Ultimately the studio and the outcomes were effective and tangible when all students, nationals and internationals, were able to understand the informalities of the city of Lima. The ideas of how these interruptions were part of this design process and how they were able to experience the city and propose new traces to take place were relevant and enlighting to the students and to the process itself. Informal cities are full of interruptions, teaching and practice can start to generate new ideas not to resolve informality but to allow it to happen in a better way.

\section{Notes}

1. Lehrer, Jonah. "A Physicist Solves the City." New York Times Magazine, Dec. 2010.

2. Lewis, Peirce E. "Axioms for Reading the Landscape: Some Guides to the American Scene." The Interpretation of Ordinary Landscape, edited by D.W. Meining, 11-32. New York: Oxford Univeristy Press, 1979

3. Bonilla Di Tolla, Enrique., and María Del Carmen. Fuentes Huerta. Lima Y El Callao : Guía De Arquitectura Y Paisaje / An Architectural and Landscape Guide. Universidad Ricardo Palma ; Junta De Andalucía, Consejería De Vivienda Y Ordenación Del Territorio, 2009.

4. Deleuze, Gilles and Felix Guattari, A Thousand Plateaus: Capitalism and Schizophrenia. Minneapolis: University of Minessota Press, 1987, 7. 